\title{
A expressão dos componentes de produtividade do trigo pela classe tecnológica e aproveitamento do nitrogênio
}

José A. G. da Silva ${ }^{1}$, Emilio G. Arenhardt ${ }^{2}$, Cleusa A. M. B. Krüger ${ }^{3}$, Osório A. Lucchese ${ }^{4}$, Magda Metz ${ }^{5} \&$ Anderson Marolli ${ }^{6}$

\section{Palavras-chave:}

Triticum aestivum L.

classe tecnológica

nitrogênio

relação $\mathrm{C} / \mathrm{N}$

\begin{abstract}
R E S U M O
A expressão dos caracteres de produção do trigo depende de estímulos genéticos e ambientais. Portanto, objetivou-se avaliar, neste estudo, a expressão de caracteres de produção em trigos a partir de sua aptidão tecnológica para elucidar se cultivares com maior valor de alveografia também exigem maior fornecimento de $\mathrm{N}$ na elaboração dos componentes de produtividade de grãos em distintos sistemas de cultivo. O delineamento experimental foi o de blocos ao acaso com quatro repetições no esquema fatorial $2 \times 4$, para as cultivar [BRS Guamirim (classe básico) e Fundacep Cristalino (classe melhorador)] e doses de nitrogênio $\left[0,60,120,180 \mathrm{~kg} \mathrm{ha}^{-1}\right.$ (sistema milho/trigo) e $0,40,80,120 \mathrm{~kg} \mathrm{ha}^{-1}$ (sistema soja/trigo)]. O maior fornecimento de $\mathrm{N}$-fertilizante na elaboração dos componentes de produção de trigo não tem apoio na classe tecnológica da cultivar, independentemente do sistema de cultivo; assim, cultivares de trigo de elevada qualidade tecnológica podem expressar valores médios nos componentes de produção superiores àqueles de menor qualidade.
\end{abstract}

Key words:

Triticum aestivum L. technological class nitrogen relation $\mathrm{C} / \mathrm{N}$

\section{The expression of the components of wheat yield by technological class and nitrogen use}

\begin{abstract}
A B S T R A C T
The expression of the characteristics of wheat production depends on the genetic and environmental stimuli. Therefore, the objective of the study was to evaluate the expression of production traits in wheat from its technological ability to elucidate whether cultivars with the highest alveography also require greater supply of $\mathrm{N}$ in the preparation of the components of grain yield in distinct cropping systems. The experimental design adopted was a randomized block with four replications in a factorial $2 \times 4$, consisting of two cultivars [BRS Guamirim (basic class) and Fundacep Cristalino (improver class)] and four levels of nitrogen $\left[0,60,120,180 \mathrm{~kg} \mathrm{ha}^{-1}\right.$ (corn/wheat system) and $0,40,80,120 \mathrm{~kg} \mathrm{ha}^{-1}$ (soybean/ wheat system)]. The highest supply of $\mathrm{N}$-fertilizer in the preparation of components of wheat production has no support in the technological class of the cultivar regardless of the cropping system. Therefore, cultivars of high quality wheat technology can express the components of mean values higher than those from lower quality produce.
\end{abstract}

Protocolo 378.13 - 27/11/2013 • Aprovado em 08/08/2014 • Publicado em 01/01/2015

${ }^{1}$ DEAg/UNIJUÍ. Ijuí, RS. E-mail: jagsfaem@yahoo.com.br

${ }^{2}$ CGF/UFPel. Pelotas, RS. E-mail: emilio.arenhardt@yahoo.com.br (Autor correspondente)

${ }^{3}$ DEAg/UNIJUÍ. Ijuí, RS. E-mail: cleusa_bianchi@yahoo.com.br

${ }^{4}$ DEAg/UNIJUÍ. Ijuí, RS. E-mail: osorio@unijui.edu.br

${ }^{5}$ DEAg/UNIJUÍ. Ijuí, RS. E-mail: magda.metz@unijui.edu.br

${ }^{6}$ MMM/UNIJUÍ. Ijuí, RS. E-mail: marollia@yahoo.com.br 


\section{INTRODUÇÃo}

O trigo é um dos cereais mais produzidos no mundo, principalmente pela grande demanda de seus derivados, que se destacam na produção de diferentes tipos de farinhas (Pinnow et al., 2013). No Brasil, o cultivo está concentrado nos estados do Paraná e Rio Grande do Sul, responsáveis por mais de $90 \%$ da produção nacional, com média de quatro milhões de toneladas (CONAB, 2013). Este montante representa menos de $50 \%$ do consumo interno fazendo com que o Brasil seja um dos principais países importadores. No incremento de produtividade e competitividade do trigo nacional é necessário o desenvolvimento de cultivares mais produtivas, com maior tolerância a fatores bióticos e abióticos, eficientes fisiologicamente no aproveitamento de luz e nutrientes e da possibilidade de segregação dos grãos e da farinha, por sua aptidão industrial (Schmidt et al., 2009; Freo et al., 2011). Neste contexto, as características genéticas, condições edafoclimáticas e técnicas de cultivo podem diferenciar o crescimento e o desenvolvimento da planta além da expressão dos componentes de produção e qualidade de grãos (Sangoi et al., 2007; Dencic et al., 2011).

Viana \& Kihl (2010) afirmam que o nitrogênio (N) é o nutriente de maior interferência na composição da planta de trigo e o mais demandado durante seu desenvolvimento. Estudos têm comprovado que tanto a produtividade (Braz et al., 2006) quanto o teor proteico dos grãos (Cazetta et al., 2008) podem ser aumentados pela adubação com N; desta forma, a produtividade do trigo está intimamente ligada ao manejo da adubação nitrogenada que, segundo Braz et al. (2006) exerce forte influência sobre o número de espigas por área e de grãos por espiga frente à variação da dose e o momento em que o $\mathrm{N}$ é fornecido. Por outro lado, o fornecimento de $\mathrm{N}$ às plantas depende, dentre outros fatores, da quantidade de MO do solo (Amado et al., 2001), da composição dos resíduos vegetais (Siqueira Neto et al., 2010), da expectativa da produtividade (CBPT, 2013) e da umidade, aeração e temperatura que interagem entre si nos sistemas de cultivo (Rocha et al., 2008). Desses fatores a composição bioquímica dos resíduos culturais é determinante em promover a mineralização ou imobilização do $\mathrm{N}$ podendo afetar as doses e épocas do $\mathrm{N}$-fertilizante frente à taxa de liberação de $\mathrm{N}$ do solo e nos tecidos em decomposição. A fertilização nitrogenada adequada e levando em consideração o tipo de cobertura vegetal, pode reduzir as perdas por lixiviação em anos chuvosos e por volatilização em anos secos e do risco de poluição das águas subterrâneas pelo acúmulo de nitrato ( $\mathrm{Ma}$ et al., 2010).

A Instrução Normativa n 38, de 30 de novembro de 2010, do MAPA (Brasil, 2010) define cinco classes de trigo destinadas à moagem, que são: melhorador, pão, doméstico, básico $\mathrm{e}$ outros usos. Desses, a classe melhorador é a mais exigida frente ao conteúdo e composição das proteínas relacionadas à força de glúten e estabilidade. Portanto, as cultivares de trigo recomendadas no sul do Brasil afora, os caracteres agronômicos também diferem daqueles ligados à classificação tecnológica dos grãos para melhor adequação do uso. Esta condição levanta a hipótese de que a classe tecnológica também pode interferir na capacidade de absorção, assimilação e conversão do nitrogênio e na elaboração da produtividade de grãos (Sangoi et al., 2007). A relação inversa entre o conteúdo de proteínas com a produtividade de grãos do trigo tem sido observada sinalizando que genótipos com maior conteúdo proteico exigem maior gasto energético na elaboração dessas proteínas (Schmidt et al., 2009) necessitando mais de N-fertilizante e/ ou residual como forma de suprir prováveis deficiências na elaboração dos componentes de produção.

O objetivo neste estudo foi avaliar a expressão de caracteres de produção em trigo a partir de sua aptidão tecnológica para elucidar se cultivares com maior valor de alveografia também exigem maior fornecimento de $\mathrm{N}$ para a produtividade de grãos em distintos sistemas de cultivo.

\section{Material e Métodos}

O trabalho foi desenvolvido no campo, no ano agrícola de 2012, no município de Augusto Pestana, RS. O solo da área experimental é classificado como Latossolo Vermelho Distroférrico Típico (Santos et al., 2006) e o clima da região, segundo classificação de Köppen, é do tipo Cfa, com verão quente sem estação seca. Na implantação do ensaio de pesquisa, por volta de dez dias antes da semeadura, foi realizada análise de solo e identificadas as seguintes características químicas do local: i) Área com resíduo de milho $(\mathrm{pH}=6,5 ; \mathrm{P}=34,4 \mathrm{mg}$ $\mathrm{dm}^{-3} ; \mathrm{K}=262 \mathrm{mg} \mathrm{dm}^{-3} ; \mathrm{MO}=3,5 \% ; \mathrm{Al}=0 \mathrm{cmol}_{\mathrm{c}} \mathrm{dm}^{-3} ; \mathrm{Ca}=$ $6,6 \mathrm{cmol}_{\mathrm{c}} \mathrm{dm}^{-3}$ e $\mathrm{Mg}=3,4 \mathrm{cmol}_{\mathrm{c}} \mathrm{dm}^{-3} \mathrm{e} \mathrm{ii)}$; Área com resíduo de soja $\left(\mathrm{pH}=6,2 ; \mathrm{P}=33,9 \mathrm{mg} \mathrm{dm}^{-3} ; \mathrm{K}=200 \mathrm{mg} \mathrm{dm}^{-3} \mathrm{MO}\right.$ $=3,4 \% ; \mathrm{Al}=0 \mathrm{cmol}_{c} \mathrm{dm}^{-3} ; \mathrm{Ca}=6,5 \mathrm{cmol}_{c} \mathrm{dm}^{-3} \mathrm{e} \mathrm{Mg}=2,5$ $\mathrm{cmol} \mathrm{dm}^{-3}$ ). A semeadura foi realizada em 15 de maio com semeadora-adubadora, em que cada parcela foi constituída de 5 linhas de $5 \mathrm{~m}$ de comprimento e espaçamento entre linhas de $0,20 \mathrm{~m}$ para compor a unidade experimental de $5 \mathrm{~m}^{2}$. Durante a execução do estudo foram efetuadas aplicações de fungicida tebuconazole de nome comercial FOLICUR ${ }^{\circ} \mathrm{CE}$ na dosagem de $0,75 \mathrm{~L} \mathrm{ha}^{-1}$ além disto, o controle de plantas daninhas foi efetuado com herbicida metsulfuron-metil na dose de $4 \mathrm{~g}$ ha $^{-1}$ do produto comercial e capinas adicionais sempre que necessário. Nos experimentos foram aplicados, na semeadura, 60 e $50 \mathrm{~kg} \mathrm{ha}^{-1}$ de $\mathrm{P}_{2} \mathrm{O}_{5}$ e $\mathrm{K}_{2} \mathrm{O}$ com base nos teores de $\mathrm{P}$ e $\mathrm{K}$ no solo, respectivamente, e na expectativa de produtividade de grãos de $2 \mathrm{t} \mathrm{ha}^{-1}$ e de $\mathrm{N}$ na base com $10 \mathrm{~kg} \mathrm{ha}^{-1}$ (exceto na unidade experimental padrão), sendo o restante aplicado em cobertura para contemplar as doses propostas no estudo quando as plantas se encontravam no estádio 3,5 da escala de Haun (1973). As doses de $\mathrm{N}$ para o trigo foram definidas a partir da dose mínima exigida com o nutriente também para uma expectativa de produtividade de $2 \mathrm{tha}^{-1} \mathrm{em}$ solo com teor de $\mathrm{MO}$ entre 2,5 e 5,0\%, no sistema milho/trigo de $60 \mathrm{~kg} \mathrm{ha}^{-1} \mathrm{e}$ no sistema soja/trigo, de $40 \mathrm{~kg} \mathrm{ha}^{-1}$ (SBCS, 2004). A definição das outras doses de $\mathrm{N}$ seguiu este intervalo nos distintos sistemas de cultivo com rápida e lenta taxa de decomposição residual incluindo a dose padrão.

$\mathrm{O}$ delineamento experimental adotado foi o de blocos ao acaso com quatro repetições em esquema fatorial $2 \times 4$, sendo duas cultivares [BRS Guamirim (classe básico) e Fundacep Cristalino (classe melhorador)] e quatro doses de nitrogênio $\left[0,60,120\right.$ e $180 \mathrm{~kg} \mathrm{ha}^{-1}$ no sistema milho/trigo e $0,40,80$ e $120 \mathrm{~kg} \mathrm{ha}^{-1}$ no sistema soja/trigo]. As cultivares indicadas representam genótipos de trigo de grande aceitação pelos 
agricultores do noroeste do RS, expressando similaridade quanto ao ciclo (precoce), estatura (baixa), acamamento (resistente) e capacidade de afilhamento (elevado). Por outro lado, com distinção quanto à classe tecnológica pela força de glúten ou alveografia (W) em Joules, com a seguinte grandeza: BRS Guamirim (262 10 $\left.0^{-4} \mathrm{~J}\right)$ e Fundacep Cristalino (384 10 $\left.0^{-4} \mathrm{~J}\right)$ (CBPT, 2013).

No estudo foram mensurados os seguintes caracteres agronômicos: 1. Produtividade de grãos (PG, em kg ha-1) pela colheita das três linhas centrais de cada parcela e convertida para a unidade de um hectare; 2. Massa de mil grãos (MMG, em g) pela pesagem de 250 grãos e multiplicado por quatro. Anterior à colheita foram coletadas, aleatoriamente, vinte espigas por parcela para proceder, em laboratório, a média das seguintes determinações: 3 . Comprimento da espiga (CE, em $\mathrm{cm}$ ); 4. Número de espiguetas férteis (NEF, contagem); 5. Número de espiguetas estéreis (NEE, contagem); 6. Massa de espiga (ME, em g); 7. Massa de grãos da espiga (MGE, em g) e 8. Número de grãos por espiga (NGE, contagem).

Após atender aos pressupostos iniciais de homogeneidade e normalidade via testes de Bartlet e Liliefors, os dados foram submetidos à análise de variância (ANAVA) para detecção da presença ou ausência de interação entre os fatores. Com base nessas informações procedeu-se ao teste de comparação de médias por Scott \& Knott em nível de 0,05 de probabilidade de erro e ao ajuste de equação de regressão de grau dois $\left(\mathrm{y}=\mathrm{b}_{0} \pm\right.$ $\mathrm{b}_{1} \mathrm{x} \pm \mathrm{b}_{2} \mathrm{x}^{2}$ ) para estimativa da máxima eficiência técnica (MET $\left.=-\left(\mathrm{b}_{1}\right) /\left(2 \mathrm{~b}_{2}\right)\right)$ e máxima eficiência econômica $(\mathrm{MEE}=[(\mathrm{t} / \mathrm{w})$ $\left.-\mathrm{b}_{1}\right] / 2 \mathrm{~b}_{2}$ ) de produtividade de grãos. Para a máxima eficiência econômica estão incluídos, no modelo matemático, o preço do produto $(\mathrm{w})$ e o preço do insumo $(\mathrm{t})$. Os valores utilizados representam os preços médios praticados na região noroeste do Rio Grande do Sul sendo o preço do insumo (nitrogênio) de $\mathrm{R} \$ 1,18 \mathrm{~kg}^{-1}$ e do produto trigo de $\mathrm{R} \$ 0,41 \mathrm{~kg}^{-1}$. Além disto foram determinados a magnitude e o sentido de associações entre as variáveis de interesse. As hipóteses foram testadas em nível de 0,05 de probabilidade de erro adotando-se o teste $t$, considerando $\mathrm{n}-2$ graus de liberdade e seguindo o modelo $\mathrm{t}$ $=r /\left[\sqrt{ }\left(1-r^{2}\right) /(n-2)\right]$, sendo $r$ o coeficiente de correlação entre os caracteres $\mathrm{X}$ e $\mathrm{Y}$ e $\mathrm{n}$ = graus de liberdade nos níveis de tratamentos considerados. Para todas essas determinações foi empregado o programa computacional Genes (Cruz, 2006).

\section{Resultados e Discussão}

As doses de $\mathrm{N}$ no sistema milho/trigo exerceram efeitos significativos sobre a PG, MMG e MGE; nos demais caracteres da espiga diferenças não foram observadas (Tabela 1). Para cultivares foi detectado efeito significativo em todos os caracteres testados. Neste sistema a interação dose versus cultivar não exerceu efeitos significativos reportando a um comportamento similar das cultivares à expressão da PG e componentes de produção do trigo. No sistema soja/trigo as doses de $\mathrm{N}$ foram efetivas sobre um número maior de variáveis, como o CE, NEF e NEE, similares às PG e MMG que também foram influenciadas (Tabela 1) condições em que todas as variáveis indicaram diferenças na comparação entre as duas cultivares. Por outro lado, a interação dose versus cultivar também não foi significativa confirmando a similaridade de comportamento entre os genótipos de classe pão e melhorador nos distintos sistemas de cultivo.

O manejo inadequado da adubação nitrogenada é um dos fatores que têm limitado o incremento da produtividade de grãos de trigo no Brasil (Benin et al., 2012) enquanto a grande variabilidade nos caracteres de produção e a qualidade de grãos das novas cultivares têm dificultado recomendações generalizadas de $\mathrm{N}$ frente às diferentes exigências nutricionais (Teixeira Filho et al., 2010). Esses autores reforçam a necessidade de estudar a resposta das cultivares à adubação nitrogenada em condições ambientais mais específicas, o que justifica a estratégia de realização deste estudo quando do envolvimento dos diferentes sistemas de sucessão com alta e reduzida taxa de liberação de $\mathrm{N}$-residual. Em gramíneas como o trigo, diferenças genéticas têm sido observadas na absorção

Tabela 1. Resumo da análise de variância da produtividade e de componentes da produção do trigo pelo efeito de doses de nitrogênio e padrão tecnológico de cultivar

\begin{tabular}{|c|c|c|c|c|c|c|c|c|c|}
\hline \multirow{2}{*}{ Fonte de variação } & \multirow{2}{*}{ GL } & \multicolumn{8}{|c|}{ Quadrado médio } \\
\hline & & PG & MMG & CE & ME & NEF & NEE & NGE & MGE \\
\hline & & \multicolumn{8}{|c|}{ Sistema milho/trigo } \\
\hline Blocos & 3 & 262539 & $98,03^{*}$ & 3,35 & 0,11 & 12,06 & 0,72 & 58,16 & 0,07 \\
\hline Dose (D) & 3 & $2428875^{\star}$ & $31,97^{\star}$ & 2,70 & $0,14^{*}$ & 6,60 & 0,44 & 52,28 & 0,05 \\
\hline Cultivar (C) & 1 & $826701^{*}$ & $13,02^{*}$ & $11,25^{\star}$ & $0,73^{\star}$ & $105,02^{*}$ & $58,08^{*}$ & $977,41^{*}$ & $0,85^{*}$ \\
\hline$D \times C$ & 3 & 149934 & 4,41 & 1,47 & 0,08 & 6,59 & 0,56 & 53,01 & 0,06 \\
\hline Erro & 21 & 74680 & 44,71 & 2,36 & 0,05 & 7,56 & 0,52 & 37,54 & 0,03 \\
\hline Total & 31 & & & & & & & & \\
\hline Média geral & & 2419,14 & 31,02 & 7,31 & 1,27 & 13,64 & 3,50 & 30,37 & 0,93 \\
\hline \multirow[t]{2}{*}{ CV (\%) } & & 16,94 & 21,55 & 21,01 & 18,66 & 20,15 & 20,65 & 20,17 & 19,61 \\
\hline & & \multicolumn{8}{|c|}{ Sistema soja/trigo } \\
\hline Blocos & 3 & 8104 & 1,89 & 0,22 & 0,02 & 0,62 & 0,66 & 44,96 & 0,04 \\
\hline Dose (D) & 3 & 387989* & $11,71^{*}$ & 0,40 & 0,01 & $2,67^{*}$ & $0,63^{*}$ & 12,03 & 0,01 \\
\hline Cultivar (C) & 1 & $304820^{*}$ & $9,13^{\star}$ & $1,49 *$ & $0,66^{*}$ & $46,41^{*}$ & $35,36^{\star}$ & 1028,60 * & $0,48 *$ \\
\hline$D \times C$ & 3 & 16621 & 3,06 & 0,11 & 0,01 & 1,71 & 0,19 & 17,24 & 0,01 \\
\hline Erro & 21 & 11504 & 0,76 & 0,17 & 0,01 & 0,61 & 0,16 & 8,77 & 0,01 \\
\hline Total & 31 & & & & & & & & \\
\hline Média geral & & 2481,28 & 31,91 & 7,53 & 1,19 & 14,09 & 3,53 & 29,57 & 0,87 \\
\hline CV (\%) & & 9,48 & 12,73 & 10,47 & 10,73 & 8,57 & 11,61 & 10,01 & 13,86 \\
\hline
\end{tabular}

*Significativo em 0,05 de probabilidade de erro; PG - Produtividade de grãos (kg ha-1); MMG - Massa de mil grãos (g); NGE - Número de grãos por espiga (n); CE - Comprimento de espiga (cm); ME - Massa de espiga (g); NEF - Número de espiguetas férteis (n); NEE - Número de espiguetas estéreis (n); MGE - Massa de grão da espiga (g); CV - Coeficiente de variação; GL - graus de liberdade 
e assimilação de nitrato $\left(\mathrm{NO}_{3}^{-}\right)$e amônio $\left(\mathrm{NH}_{4}^{+}\right)$, responsáveis pelo consumo de 15 a $23 \%$ do total de carboidratos fixados pela planta (Golick et al., 2003). Portanto, a maior eficiência da cultivar na absorção do $\mathrm{N}$ e sua conversão em proteína se direcionam para o consumo ainda maior de carboidratos, fato que pode reduzir o acúmulo de amido e comprometer a expressão da PG (Schmidt et al., 2009). Estudando cultivares de trigo de distintas classes industrial, Benin et al. (2012) detectaram diferenças genéticas na expressão do NGE e MMG porém sobre a PG alterações não foram observadas inclusive a interação dose x cultivar não foi detectada, condição similar à observado neste estudo.

Apesar de Payne (1987) ter argumentado que genótipos de trigo de elevada qualidade industrial tendem a expressar maior conteúdo de proteína no grão em relação àquele com menor qualidade, a hipótese de que a classe tecnológica, que tem por base a força de glúten (W), não esteja ligada à expressão dos componentes da inflorescência do trigo, se torna fortalecida, condição em que o elevado W de uma cultivar não exigiria, necessariamente, maior suporte de $\mathrm{N}$ em promover desenvolvimento adequado da espiga. Inclusive, em trigos brasileiros de elevada e reduzida qualidade de farinha analisada pela alveografia (W) foi detectada ausência total de correlação do W com a PG, massa do hectolitro e MMG, indicando a presença de genes que, independentemente, direcionam a expressão da produtividade de grãos e outros que atuam sobre a qualidade da farinha (Schmidt et al., 2009).

No sistema milho/trigo as doses de $\mathrm{N}$ proporcionaram valor de quadrado médio com magnitute superior à da cultivar sobre os caracteres PG e MMG indicando a maior efetividade do N na alteração dessas variáveis (Tabela 1). Por outro lado, a fonte de variação cultivar indicou maior contribuição de alteração nos caracteres da espiga. No sistema soja/trigo também foram detectadas em condições similares porém com maior similaridade para ambas as fontes de variação na magnitude de quadrado médio da PG e MMG. É provável que referida condição seja favorecida pela maior disponibilidade de $\mathrm{N}$-residual neste sistema promovendo condições mais favoráveis de expressão e estabilidade dessas variáveis. A variabilidade genética nos caracteres da inflorescência do trigo tem sido fortemente observada em trigos brasileiros (Silva et al., 2006) e a ação do N-fertilizante sobre os processos fisiológicos de produção tem-se mostrado mais efetiva em condições mais restritivas de N-residual (Heinemann et al., 2006). No entanto, a integração de fertilizantes minerais e orgânicos também desponta como estratégia eficiente em incrementar os componentes ligados à produtividade do trigo, trazendo melhor aproveitamento do $\mathrm{N}$-fertilizante quando combinado com a liberação do N-residual contido na cobertura vegetal de reduzida relação C/N (Nunes et al., 2011).

Independentemente da condição de cultivo (Tabela 1) a ausência de interação justifica a forma de apresentação das médias na Tabela 2 e a proposta de uma única equação em cada sistema subsidiar a interpretação biológica da eficiência de aproveitamento do nitrogênio. Portanto, se constatou, no sistema milho/trigo, que a cultivar Fundacep Cristalino teve produtividade de grãos superior à da BRS Guamirim condição que, pelos componentes de produção da inflorescência desta cultivar, denota uma contribuição via incremento do NEF, NGE e reduzido NEE (Tabela 2). Além disto, a maior produtividade de grãos também foi constatada para a cultivar Fundacep Cristalino no sistema soja/trigo, possivelmente fortalecida pela maior expressão das ME, NEF e NGE e reduzido NEE. Esta observação dá solidez à hipótese de que cultivares de trigo de grande potencial genético para elevada qualidade tecnológica (classe melhorador) podem expressar valores médios de produção e componentes da espiga superiores àqueles de classe tecnológica inferior. Ressalta-se que, independente dos sistemas de cultivo, tanto a MMG e a MGE trazem forte contribuição para a cultivar BRS Guamirim em relação à Fundacep Cristalino mostrando elevada habilidade na conversão e acúmulo de fotoassimilados voltado ao enchimento de grãos; entretanto, por mais que se reflita na maior habilidade do genótipo à expressão da MMG, esta condição não foi suficiente para alterar a resposta superior da cultivar Fundacep Cristalino quanto à produtividade de grãos. Benin et al. (2012) observaram variabilidade nas cultivares de trigo em resposta ao aproveitamento do $\mathrm{N}$ e que o efeito positivo observado nos níveis de fertilização se deve à melhor expressão dos componentes de produtividade de grãos. Além disto, os autores identificaram que a variabilidade das cultivares evidencia maior contribuição de alteração da PG que os níveis de fertilização com $\mathrm{N}$ mostrando a importância da escolha correta de uma cultivar para melhor aproveitamento dos estímulos ambientais; inclusive notaram melhor resposta dos caracteres de produção quando a precipitação pluvial não foi limitante, condição também observada por Anjos \& Nery (2005).

Verificou-se, em estudos com trigo e triticale, que a elevação das doses do $\mathrm{N}$-fertilizante incrementou significativamente o teor de proteína nos grãos e o valor da alveografia trazendo benefícios em incrementar o NGE na inflorescência do trigo (Cazetta et al., 2008).

$\mathrm{Na}$ Tabela 2 são apresentados o resumo da análise de regressão e os parâmetros da equação sobre a produtividade de grãos, buscando definir a máxima eficiência técnica e econômica pelo uso do $\mathrm{N}$; portanto e independente das cultivares testadas, o comportamento observado nos diferentes sistemas de cultivo mostrou tendência quadrática significativa na expressão da PG e com parâmetro de inclinação de grau dois $\left(b_{i x}\right)$ também significativo. Os coeficientes de determinação das equações estão em mais de $90 \%$ representados próximos à linha de tendência, expressando confiabilidade dos dados e das inferências a serem obtidas; desta forma e independente das cultivares testadas de distinto padrão comercial, o sistema milho/trigo mostrou que a máxima eficiência técnica (MET) pelo uso do $\mathrm{N}$ foi obtida com $114 \mathrm{~kg} \mathrm{ha}^{-1}$, gerando uma expectativa de produtividade estimada $\left(\mathrm{PG}_{\mathrm{E}}\right)$ de $2864 \mathrm{~kg} \mathrm{ha}^{-1}$. Nesta condição, a máxima eficiência econômica foi a aplicação de $84 \mathrm{~kg} \mathrm{ha}^{-1}$ de $\mathrm{N}$, gerando uma estimativa de produtividade de grãos de $2790 \mathrm{~kg} \mathrm{ha}^{-1}$ cujos resultados indicam que em um sistema de alta relação $\mathrm{C} / \mathrm{N}$ a MEE reduziu consideravelmente o uso do elemento químico e com produtividade de grãos próxima à obtida na MET. Afora isto e quando o estudo foi realizado no sistema soja/trigo, o uso do $\mathrm{N}$ pelas cultivares buscando a MET foi ainda mais reduzido, com $78 \mathrm{~kg} \mathrm{ha}^{-1}$ para uma expectativa de produtividade de grãos de $2822 \mathrm{~kg} \mathrm{ha}^{-1}$ isto é, uma redução significativa do $\mathrm{N}$ em mais de $35 \mathrm{~kg} \mathrm{ha}^{-1}$ para 
Tabela 2. Médias da produtividade de grãos e componentes de produção do trigo e equação de regressão na estimativa da produtividade de grãos estimada $\left(\mathrm{PG}_{\mathrm{E}}\right.$ ) e da máxima eficiência técnica (MET) e econômica (MEE) nos sistemas de cultivo

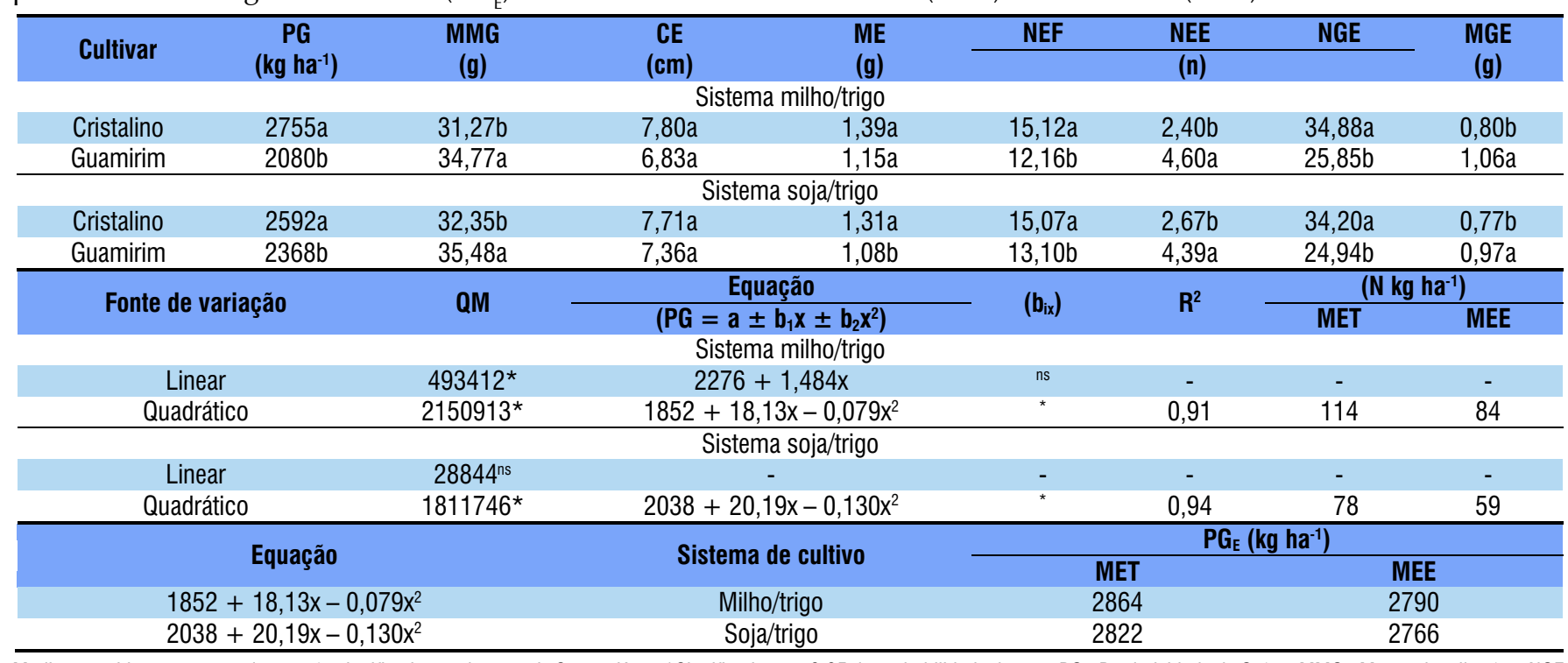

Medias seguidas por mesma letras não significativas pelo teste de Scott e Knott * Significativo em 0,05 de probabilidade de erro; PG - Produtividade de Grãos; MMG - Massa de mil grãos; NGE - Número de grãos por espiga; CE - Comprimento da espiga; ME - Massa de espiga; NEF - Número de espiguetas férteis; NEE - Número de espiguetas estéreis; MGE - Massa de grão da espiga

uma expectativa de PG similar entre os sistemas de cultivo. A MEE no sistema soja/trigo foi obtida com apenas $59 \mathrm{~kg} \mathrm{ha}^{-1}$ de $\mathrm{N}$ para uma $\mathrm{PG}_{\mathrm{E}}$ de $2766 \mathrm{~kg} \mathrm{ha}^{-1}$. O incremento do $\mathrm{N}$ em promover elevação da $\mathrm{PG}$ apresenta modificações positivas nos componentes de produção do trigo sobremaneira no número de afilhos férteis e de grãos na espiga (Benin et al., 2012). Tal condição viabiliza a recomendação técnica que propõe a aplicação do $\mathrm{N}$ na terceira folha expandida com colar estádio no qual ocorrem, simultaneamente, a indução do afilhamento e a diferenciação do meristema reprodutivo (Espíndula et al., 2010). Ressalta-se que a redução significativa de $\mathrm{N}$-fertilizante obtida neste estudo confirma os resultados obtidos por Braz et al. (2006) ao observarem que para uma mesma produtividade de trigo a necessidade de adubação nitrogenada é menor quando o mesmo é cultivado sobre leguminosas. Pinnow et al. (2013) reportam que o emprego de adubos verdes maximiza a qualidade de panificação e a produtividade do trigo reduzindo a demanda e as perdas da adubação nitrogenada mineral.

Buscando elucidar o relacionamento entre os caracteres base nos distintos sistemas de cultivo e das características tecnológicas de cultivar apresenta-se, na Tabela 3, a análise de correlação da PG e MMG com aqueles ligados à composição da espiga do trigo. No sistema soja/trigo foi detectada relação positiva da PG com a MMG mas esta mesma correlação foi alterada em um sistema de alta relação C/N (sistema milho/ trigo) para uma relação negativa.

Nos dois sistemas de cultivo a correlação direta e positiva da PG x ME foi efetiva, reportando tendência similar de incremento da PG pela maior expressão do ME. Fato curioso os NEF, NEE, NGE e MGE se correlacionarem significativa e positivamente com a PG apenas sobre o sistema milho/trigo sugerindo que uma disponibilidade maior de N-residual poderia atuar diretamente sobre esses caracteres visando incrementar a PG, condição passível de justificar a ausência de relação linear no sistema soja/trigo. $\mathrm{Na}$ análise da $\mathrm{MMG}$ no sistema soja/trigo houve favorecimento desta variável pela relação direta e positiva com as ME, NEF, NGE e MGE (Tabela 3). Por outro lado, no sistema milho/trigo todos os caracteres da espiga indicaram relação negativa sobre a MMG. Tais condições indicam que a disponibilidade de N-residual

Tabela 3. Correlação da produtividade, massa de mil grãos e componentes de produção do trigo para sistema de cultivo, cultivar e análise conjunta (sistema de cultivo + cultivar)

\begin{tabular}{|c|c|c|c|c|c|}
\hline \multirow{2}{*}{ Variáveis } & \multicolumn{2}{|c|}{ Sistema (r) } & \multicolumn{2}{|c|}{ Cultivar (r) } & \multirow{2}{*}{$\begin{array}{c}\text { Conjunta (r) } \\
\text { (Sistema+Cultivar) }\end{array}$} \\
\hline & Soja/trigo & Milho/trigo & Cristalino & Guamirim & \\
\hline$P G \times M M G$ & $0,55^{\star}$ & $-0,34^{*}$ & 0,17 & $0,45^{*}$ & 0,12 \\
\hline$P G \times C E$ & 0,08 & $0,42^{*}$ & $0,34^{*}$ & 0,07 & $0,28^{*}$ \\
\hline$P G \times M E$ & $0,31^{*}$ & $0,49^{*}$ & $0,42^{*}$ & 0,13 & $0,41^{*}$ \\
\hline$P G \times N E F$ & 0,21 & $0,53^{*}$ & 0,27 & 0,2 & $0,38^{*}$ \\
\hline PG $\times$ NEE & $-0,03$ & $-0,41^{*}$ & $-0,01$ & $-0,15$ & $-0,25^{\star}$ \\
\hline$P G \times N G E$ & 0,03 & $0,35^{\star}$ & $-0,01$ & $-0,08$ & $0,21^{*}$ \\
\hline$P G \times M G E$ & 0,21 & $0,34^{*}$ & 0,16 & 0,06 & $0,29 *$ \\
\hline MMG x CE & 0,18 & $-0,41^{*}$ & 0,15 & $-0,06$ & $-0,08$ \\
\hline MMG $\times$ PE & $0,53^{*}$ & $-0,56^{\star}$ & 0,05 & $0,63^{*}$ & 0,05 \\
\hline MMG $\times$ NEF & $0,32^{\star}$ & $-0,69 *$ & $0,28^{*}$ & $-0,07$ & $-0,14$ \\
\hline MMG x NEE & 0,21 & $-0,74^{*}$ & $-0,21$ & $-0,06$ & $-0,10$ \\
\hline MMG $\times$ NGE & $0,31^{*}$ & $-0,77^{*}$ & 0,16 & 0,02 & $-0,13$ \\
\hline MMG x MGE & $0,31^{*}$ & $-0,74^{*}$ & $-0,13$ & 0,15 & $-0,13$ \\
\hline
\end{tabular}

${ }^{*}$ Significativo em 0,05 de probabilidade de erro; PG - Produtividade de grãos (kg ha-1); MMG - Massa de mil grãos (g); NGE - Número de grãos por espiga (n); CE - Comprimento da espiga (cm); ME - Massa de espiga (g); NEF - Número de espiguetas férteis (n); NEE - Número de espiguetas estéreis (n); MGE - Massa de grão da espiga (g) 
reporta de um favorecimento à expressão dos componentes ligados à inflorescência do trigo e, consequentemente à $\mathrm{MMG}$, justificando as inferências formuladas na Tabela 2 .

No relacionamento das variáveis sobre cada cultivar a contribuição de incremento da PG no genótipo Fundacep Cristalino ocorreu pelo favorecimento do CE e ME (Tabela 3). Por outro lado, na cultivar BRS Guamirim a contribuição foi obtida via MMG, buscando maior expressão da PG. Estes resultados vão ao encontro daqueles observados na Tabela 2 com os valores médios elevados da Fundacep Cristalino na expressão do CE e ME e da maior expressão da MMG pela BRS Guamirim; por outro lado, na expressão da MMG, efeitos positivos podem ser obtidos via ME para a BRS Guamirim e do NEF na Fundacep Cristalino; contudo, na análise de correlação conjunta (sistemas+cultivar) constatou-se relação significativa e positiva via CE, ME, NEF, NGE e MGE na expressão da PG, exceto no NEE. Por sua vez, a totalidade dos caracteres da inflorescência do trigo não mostrou relação direta sobre a expressão da MMG. Silva et al. (2006) observaram que para incrementar simultaneamente o NGE e MGE a variável massa hectolítrica mostrou relação direta e positiva; inclusive, o favorecimento da ME foi decisivo em trazer efeitos indiretos e positivos em maximizar a PG. Guercio \& Camargo (2011) observaram correlação entre a produção de grãos e o número de espigas por planta, número de grãos por espiga e massa de mil grãos, condição que poderia viabilizar uma análise indireta buscando identificar genótipos mais produtivos de trigo. Nunes et al. (2011) argumentam que um entendimento melhor da expressão nos componentes de produção do trigo requer uma análise mais apurada dos efeitos genéticos e ambientais. Ressalta-se que a produtividade de grãos em trigo é definida pela expressão do número de afilhos férteis, NGE e massa média de grãos, componentes fortemente afetados pela interação genótipo $\mathrm{x}$ ambiente (Silva et al., 2006). Estudando as interações entre doses de $\mathrm{N}$ em distintos sistemas de cultivo, Nunes et al. (2011) identificaram melhor expressão dos componentes de produção quando o trigo foi cultivado após crotalária, espécie de elevada taxa de liberação de N-residual, interagindo beneficamente com menores doses do N-fertilizante. Ressaltam-se, por fim, os benefícios que podem trazer a qualidade ambiental pela redução de perdas de lixiviação e volatilização do elemento químico e redução de custos ao agricultor.

\section{Conclusões}

1. O maior fornecimento de $\mathrm{N}$-fertilizante na elaboração dos componentes de produção de trigo não tem apoio na classe tecnológica da cultivar, independentemente da cultura anterior (soja ou milho).

2. Cultivares de trigo de elevada qualidade tecnológica podem expressar valores médios nos componentes de produção superiores àqueles de menor qualidade.

\section{Agradecimentos}

Ao CNPq, à FAPERGS e à UNIJUI, pelo aporte dos recursos destinados ao desenvolvimento deste estudo e bolsas de pesquisa.

\section{Literatura Citada}

Amado, T. J. C.; Bayer, C.; Eltz F. L. F.; Brum, A. C. R.. Potencial de culturas de cobertura em acumular carbono e nitrogênio no solo no plantio direto e a melhoria da qualidade ambiental. Revista Brasileira de Ciência do Solo, v.25, p.189-197, 2001. http://dx.doi. org/10.1590/S0100-06832001000100020

Anjos, I. B.; Nery, J. T. Variáveis meteorológicas associadas ao rendimento de grãos no estado do Paraná. Acta Scientiarum. Agronomy, v.27, p.133-144, 2005.

Benin, G.; Bornhofen, E.; Beche, E.; Pagliosa, E. S.; Silva, C. L. S.; Pinnow, C. Agronomic performance of wheat cultivars in response to nitrogen fertilization levels. Acta Scientiarum. Agronomy, v.34, p.275-283, 2012.

Brasil. Ministério da Agricultura, Pecuária e Abastecimento. Instrução Normativa n 38, de 30 de novembro de 2010.

Braz, A. J. B. P.; Silveira, P. M.; Kliemann, H. J.; Zimmermann, F. J. P. Adubação nitrogenada em cobertura na cultura do trigo em sistema plantio direto após diferentes culturas. Ciência e Agrotecnologia, v.30, p.193-198, 2006. http://dx.doi.org/10.1590/ S1413-70542006000200001

Cazetta, D. A.; Fornasieri Filho, D.; Arf, O.; Germani, R. Qualidade industrial de cultivares de trigo e triticale submetidos à adubação nitrogenada no sistema de plantio direto. Bragantia, v.67, p.741-750, 2008. http://dx.doi.org/10.1590/S000687052008000300024

CBPT - Comissão Brasileira de Pesquisa de Trigo e Triticale. Informações técnicas para a cultura do trigo e triticale. Londrina: IAPAR, 2013. 220p.

CONAB - Companhia Nacional de Abastecimento. Séries históricas de área, produção e produtividade de grãos: Safra 2013 de trigo. http://www.conab.gov.br. 25 Nov. 2013.

Cruz, C. D. Programa Genes: Biometria. Viçosa: UFV. 2006. 382p.

Dencic, S.; Mladenov, N.; Kobiljski, B. Effects of genotype and environment on breadmaking quality in wheat. International Journal of Plant Production, v.5, p.71-82, 2011.

Espíndula, M. C.; Rocha, V. S.; Souza, M. A.; Grossi, J. A. S.; Souza, L. T. Doses e formas de aplicação de nitrogênio no desenvolvimento e produção da cultura do trigo. Ciência e Agrotecnologia, v.34, p.1404-1411, 2010.

Freo, J. D.; Rosso, N. D.; Moraes, L. B. D.; Dias, A. R. G.; Elias, M. C.; Gutkoski, L. C. Physicochemical properties and silicon content in wheat flour treated with diatomaceous earth and conventionally stored. Journal of Stored Products Research, v.47, p.316-320, 2011. http://dx.doi.org/10.1016/j.jspr.2011.05.001

Golik, S. I.; Chidichimo, H. O.; Pérez, D.; Pane, L. Acumulación, removilización, absorción postantesis y eficiencia de utilización de nitrógeno en trigo bajo diferentes labranzas y fertilizaciones, Pesquisa Agropecuária Brasileira, v.38, p.619-626, 2003. http:// dx.doi.org/10.1590/S0100-204X2003000500010

Guercio, A. M. F.; Camargo, C. E. O. Herdabilidade e correlações entre caracteres agronômicos em populações híbridas de trigo duro. Bragantia, v.70, p.19-24, 2011. http://dx.doi.org/10.1590/S000687052011000100004

Haun, J. R. Determination of wheat growth-environments relationships. Agronomy Journal, v.65, p.813-816, 1973. http://dx.doi.org/10.2134/ agronj1973.00021962006500050042x 
Heinemann, A. B.; Stone, L. F.; Didonet, A. D.; Trindade, M. G.; Soares, B. B.; Moreira, J. A. A.; Canovas, A. D. Eficiência de uso da radiação solar na produtividade de trigo decorrente da adubação nitrogenada. Revista Brasileira de Engenharia Agrícola e Ambiental, v.10, p.352-356, 2006. http://dx.doi.org/10.1590/ S1415-43662006000200015

Ma, B. L.; Wu, T. Y.; Tremblay, N.; Deen, W.; Mclaughlin, N. B.; Morrison, M.; Stewart, G. On-farm assessment of the amount and timing of nitrogen fertilizer on ammonia volatilization. Agronomy Journal, v.102, p.134-144, 2010. http://dx.doi.org/10.2134/agronj2009.0021

Nunes, A. S.; Souza, L. C. F.; Vitorino, A. C. T.; Mota, L. H. S. Adubos verdes e doses de nitrogênio em cobertura na cultura do trigo sob plantio direto. Semina: Ciências Agrárias, v.32, p.1375-1384, 2011. http://dx.doi.org/10.5433/1679-0359.2011v32n4p1375

Payne, P. I. Genetics of wheat storage proteins and the effect of allelic variation on bread-making quality. Annual Review of Plant Physiology, v.38, p.141-153, 1987. http://dx.doi.org/10.1146/ annurev.pp.38.060187.001041

Pinnow, C.; Benin, G.; Viola, R.; Silva, C. L. S.; Gutkoski, L. C.; Cassol, L. C. Qualidade industrial do trigo em resposta à adubação verde e doses de nitrogênio. Bragantia, v.72, p.20-28, 2013. http://dx.doi. org/10.1590/S0006-87052013005000019

Rocha, F. A.; Martinez, M. A.; Matos, A. T.; Cantarutti, R. B.; Silva, J. O. Modelo numérico do transporte de nitrogênio no solo. Parte II: Reações biológicas durante a lixiviação. Revista Brasileira de Engenharia Agrícola e Ambiental, v.12, p.54-61, 2008. http://dx.doi. org/10.1590/S1415-43662008000100008

Sangoi, L.; Berns, A. C.; Almeida, M. L.; Zanin, C. G. Schweitzer, C. Características agronômicas de cultivares de trigo em resposta à época da adubação nitrogenada de cobertura. Ciência Rural, v.37, p.15641570, 2007. http://dx.doi.org/10.1590/S0103-84782007000600010
Santos, H. G. dos; Jacomine, P. K. T.; Anjos, L. H. C. dos; Oliveira, V. A. de; Oliveira, J.B. de; Coelho, M. R.; Lumbreras, J. F.; Cunha, T. J. F. (ed.). Sistema brasileiro de classificação de solos. 2.ed. Rio de Janeiro: Embrapa Solos, 2006. 306p

SBCS - Sociedade Brasileira de Ciência do Solo. Manual de adubação e calagem para os Estados do Rio Grande do Sul e de Santa Catarina. 10. ed. Porto Alegre: SBCS, 2004. 400p.

Schmidt, D. A. M.; Carvalho, F. I. F.; Oliveira, A. C.; Silva, J. A. G.; Bertan, I.; Valério, I. P.; Hartwig, I.; Silveira, G.; Gutkoski, L. C. Variabilidade genética em trigos brasileiros a partir de caracteres componentes da qualidade industrial e produção de grãos. Bragantia, v.68, p.43-52, 2009. http://dx.doi.org/10.1590/S000687052009000100006

Silva, J. A. G.; Carvalho, F. I. F.; Oliveira, A. C.; Vieira, E. A.; Benin, G.; Valério, I. P.; Carvalho, M. F.; Finatto, T.; Busato, C. C.; Ribeiro, G. Correlação de acamamento com rendimento de grãos e outros caracteres de interesse agronômico em plantas de trigo. Ciência Rural, v.36, p.756-764, 2006. http://dx.doi.org/10.1590/S010384782006000300006

Siqueira Neto, M.; Piccolo, M. C.; Venzke Filho, S. P.; Feigl, B. J.; Cerri, C. C. Mineralização e desnitrificação do nitrogênio no solo sob sistema plantio direto. Bragantia, v.69, p.923-936, 2010. http:// dx.doi.org/10.1590/S0006-87052010000400019

Teixeira Filho, M. C. M.; Buzetti, S.; Andreotti, M.; Arf, O.; Benett, C. G. S. Doses, fontes e épocas de aplicação de nitrogênio em trigo irrigado em plantio direto. Pesquisa Agropecuária Brasileira, v.45, p.797-804, 2010. http://dx.doi.org/10.1590/S0100204X2010000800004

Viana, E. M.; Kiehl, J. C. Doses de nitrogênio e potássio no crescimento do trigo. Bragantia, v.69, p.975-982, 2010. http://dx.doi.org/10.1590/ S0006-87052010000400024 